\title{
The Performance of Urea-Intercalated and Delaminated Kaolinites-Adsorption Kinetics Involving Copper and Lead
}

\author{
Denis L. Guerra and Claudio Airoldi*
}

\author{
Instituto de Química, Universidade Estadual de Campinas, CP 6154, 13084-971 Campinas-SP, Brazil
}

\begin{abstract}
Amostras brasileiras de caulinita foram usadas no estudo dos processos de intercalação com uréia $\left(\mathrm{K}_{\mathrm{UR}}\right)$ e de deslaminação $\left(\mathrm{K}_{\mathrm{UR} / \mathrm{DL}}\right)$. A amostra intercalada foi deslaminada por tratamento com ultra-som em solução ácida. A distância basal inicial de $0,72 \mathrm{~nm}$ passa a 1,08 $\mathrm{nm}$ com aumento na área superficial de 20,3 para 90,5 $\mathrm{m}^{2} \mathrm{~g}^{-1}$ para $\mathrm{K}_{\mathrm{NAT}}$ e $\mathrm{K}_{\mathrm{UR} / \mathrm{DL}}$. Amostras de argila intercalada e deslaminada adsorveram cátions cobre e chumbo na interface sólido/líquido. Os modelos de isotermas de adsorção de Langmuir, Redlich-Peterson e Toth foram utilizados em processo de regressão linear e não linear para a obtenção de valores de b e $\mathrm{K}_{\mathrm{L}}$ para todas as amostras de caulinita. A capacidade de adsorção mais alta, de $12,8 \mathrm{mmol} \mathrm{g}^{-1}$, foi obtida com a caulinita deslaminada. Os parâmetros cinéticos analisados pelos modelos de Lagergren e Elovich forneceram um bom ajuste para uma reação de pseudo-segunda ordem com valores de $\mathrm{k}_{2}$ variando de 5,0 a 11,0 e de 4,9 a 13,0 $\mathrm{mmol}^{-1} \mathrm{~min}^{-1}$ para cátions cobre e chumbo, respectivamente.
\end{abstract}

Brazilian kaolinite clay was used to study urea intercalation $\left(\mathrm{K}_{\mathrm{UR}}\right)$ and delamination $\left(\mathrm{K}_{\mathrm{UR} / \mathrm{DL}}\right)$ processes. The intercalated sample was delaminated by ultrasonic treatment in acidic solution. The basal distance changed from 0.72 to $1.08 \mathrm{~nm}$ with increasing surface area from 20.3 to $90.5 \mathrm{~m}^{2} \mathrm{~g}^{-1}$ for $\mathrm{K}_{\mathrm{UR}}$ and $\mathrm{K}_{\mathrm{UR} / \mathrm{DL}}$. Suspended pristine, intercalated and delaminated clays at $\mathrm{pH} 5.0$ adsorbed copper and lead cations at the solid/liquid interface. The Langmuir, Redlich-Peterson and Toth adsorption isotherm models were employed in linear and nonlinear regression processes, to give $\mathrm{b}$ and $\mathrm{K}_{\mathrm{L}}$ values for all kaolinites. The highest adsorption capacity of $12.8 \mathrm{mmol} \mathrm{g}^{-1}$ was obtained with delaminated kaolinite. The kinetic parameters analyzed by the Lagergren and Elovich models gave a good fit for a pseudo-second order reaction with $\mathrm{k}_{2}$ in the 5.0 to 11.0 and the 4.9 to $13.0 \mathrm{mmol}^{-1} \mathrm{~min}^{-1}$ ranges for copper and lead cations, respectively.

Keywords: kaolinite, adsorption, heavy metals, kinetics, delamination

\section{Introduction}

Some undesirable heavy metals can be removed from aqueous solution through chemical precipitation, ion exchange, electrodeposition, solvent extraction, membrane separation, reverse osmosis and adsorption processes. For this last procedure, the development of low cost adsorbents with easy manipulation and regeneration for possible reuse has been an object of significant attention, mainly when effluents are involved. Various conventional and non-conventional adsorbents have been explored for removal of different metal ions from aqueous solutions. ${ }^{1-7}$ For example, materials containing micro and macropores, such as pillared and intercalated/delaminated clays, are often employed in such operations. In particular, kaolinite

\footnotetext{
*e-mail: airoldi@iqm.unicamp.br
}

and smectite group clay minerals have been successfully explored in many adsorption procedures. ${ }^{8-10}$

From the structural viewpoint, kaolinite is a 1:1 dioctahedral aluminosilicate with two distinct basal cleavage faces. ${ }^{11}$ One of them consists of a tetrahedral siloxane surface formed by very chemically inert -Si-O-Sibonds, while the other is constituted by an octahedral gibbsite sheet, $\mathrm{Al}(\mathrm{OH})_{3}$. The neutral layered 1:1 structure can be disrupted and the broken bonds have the ability to accommodate $\mathrm{OH}$ groups.

Kaolinite is one of the most important clay minerals and its diverse industrial applications depend on the ability to modify the original properties for different uses. The methodology of surface modification includes, in principle, intercalation of species such as urea, dimethylsulfoxide and potassium acetate, among others. As expected, ion intercalation into the kaolinite structure results in changing 
the amount of reactive acidic and basic sites on the internal and external surfaces. ${ }^{12-18}$

The aim of the present investigation is to study the structural and physical-chemical characteristics of three different kaolinite forms: natural, urea-intercalated and also urea intercalated and delaminated samples. Various parameters, such as synthetic intercalation and delaminated procedures, the influence caused on adsorption capacity due to the intercalation and delamination processes, the kinetics of adsorption and applications for divalent copper and lead from aqueous solution, were explored. The Langmuir, Redlich-Peterson and Toth adsorption isotherm models have been applied to fit the experimental data by using linear and nonlinear regressions. The effect of the variation of parameters on the structure of the modified kaolinite samples was analyzed by different techniques and the kinetics of adsorption was studied through the Lagergren and Elovich models, by applying linear and nonlinear regressions.

\section{Experimental}

\section{Raw material}

The clay sample used in this investigation was obtained from the Perus area, São Paulo state, Southeast of Brazil. A natural kaolinite sample, named $\mathrm{K}_{\mathrm{NAT}}$, with less than $2 \mu \mathrm{m}$ particles, was separated by sedimentation. The cation-exchange capacity (CEC) was measured in order to evaluate the potential use of that clay for intercalation and delamination. The exchange was followed by the ammonium acetate method with a concentration of $2.0 \mathrm{~mol} \mathrm{dm}^{-3}$ at $\mathrm{pH} 8.0$, giving $0.15 \mathrm{mmol} \mathrm{g}^{-1}$ on an airdried basis. ${ }^{11}$

\section{Sample preparation}

The samples were dried at $333 \mathrm{~K}$ to reach humidity in the 12 to $15 \%$ range, controlled by thermogravimetry. The solid was ground and passed through a USS sieve No. 200 (0.074 mm). Part of the kaolinite clay was dispersed in doubly deionised water for several hours and was further purified using an established method. ${ }^{11}$ The sample examined by powder $\mathrm{X}$-ray diffractometry identified the presence of clay similar to those resulting from conventional sample preparation procedures, such as air-dried oriented mounts, ethylene glycol solvated and heated at 573 and $773 \mathrm{~K}$.

\section{Intercalation and delamination procedures}

The kaolinite sample was intercalated by mixing about
$10 \mathrm{~g}$ of the clay with $2.0 \mathrm{~g}$ of urea through a grinding procedure, in an agate vibratory mill for a period of $360 \mathrm{~min}$ at room temperature. The resulting solid, named $\mathrm{K}_{\mathrm{UR}}$, was washed with deionized water and dried for $2 \mathrm{~h}$ at $333 \mathrm{~K}$. To perform the delamination, initially $5 \mathrm{~g}$ of the intercalated $\mathrm{K}_{\mathrm{UR}}$ sample was suspended in $5.0 \mathrm{~cm}^{3}$ of $0.10 \mathrm{mmol} \mathrm{dm}^{-3}$ hydrochloric acid solution. This suspension was maintained for $1 \mathrm{~h}$ in an ultrasonic bath, Bedelin RK 1028 ultrasonic cleaner, operated at $35 \mathrm{kHz}$. After filtration through sintered glass, the solid named $\mathrm{K}_{\mathrm{UR} / \mathrm{DL}}$ was dried in vacuum for $12 \mathrm{~h}$ at room temperature.

\section{Adsorption}

The batch adsorption methodology studies were carried out with about $60 \mathrm{mg}$ of the natural, intercalated or delaminated kaolinite samples in a series of flasks containing $20.0 \mathrm{~cm}^{3}$ of aqueous solution containing the metal ion, varying in concentration from $7.0 \times 10^{-3}$ to $7.0 \times 10^{-4} \mathrm{~mol} \mathrm{dm}^{-3}$ at $298 \pm 1 \mathrm{~K}$. Firstly, the effect of $\mathrm{pH}$ on adsorption for all clay samples was evaluated by varying this parameter over the range from 1.0 to 5.0, with addition of $0.10 \mathrm{~mol} \mathrm{dm}^{-3}$ of nitric acid or sodium hydroxide. For these determinations, the number of moles adsorbed per gram $\left(\mathrm{N}_{\mathrm{f}}\right)$ is calculated by the difference between the number of moles initially present $\left(\mathrm{N}_{\mathrm{i}}\right)$ and the number of moles of metal remaining in the supernatant $\left(\mathrm{N}_{\mathrm{s}}\right)$ divided by the mass $(\mathrm{m})$ of the compound, ${ }^{19-21}$ using equation 1 .

$\mathrm{N}_{\mathrm{f}}=\frac{\left(\mathrm{N}_{\mathrm{i}}-\mathrm{N}_{\mathrm{S}}\right)}{\mathrm{m}}$

The time required to reach equilibrium was obtained through specific isotherms, by considering concentration versus time. Equilibrium was reached in less than $10 \mathrm{~h}$; however, a time period of $12 \mathrm{~h}$ was chosen to ensure maximum adsorption. Then, after establishing this experimental condition, the same procedure was used to obtain the isotherm with maximum adsorption at chosen pH. Based on these data the final concentration isotherm was obtained using this condition, which enabled obtaining the maxima adsorption capacity. Thus, the number of moles of cation adsorbed $\left(\mathrm{N}_{\mathrm{f}}\right)$ increased with its concentration in the supernatant $\left(\mathrm{C}_{\mathrm{s}}\right)$ as a function of $\mathrm{pH}$ during $12 \mathrm{~h}$, until a plateau was reached, indicating total saturation of the acidic centers in the layered structure. ${ }^{19-21}$

The most commonly used isotherm is that proposed by Langmuir, which was originally derived for gas adsorption on planar surfaces such as glass, mica and platinum. However, this procedure has also been applied to cation adsorption on porous surfaces in the classical 
Langmuir form. For this adsorption model, the amount of the adsorbate in the equilibrium solution upon reaching the plateau of the isotherm enabled determination of the $\mathrm{K}_{\mathrm{L}}$ and $b$ parameters, which reflect the activity of the surface for the adsorbing species. The constant $b$ establishes the upper limit for adsorption and represents the maximum value, determined by the number of reactive surface sites in kaolinite structure, ${ }^{19-21}$ as represented by equation 2 :

$\mathrm{N}_{\mathrm{f}}=\frac{\mathrm{K}_{\mathrm{L}} \mathrm{bC}_{\mathrm{S}}}{1+\mathrm{bC}_{\mathrm{S}}}$

Then, the $\mathrm{Cs} / \mathrm{N}_{\mathrm{f}}$ and the so-called distribution coefficient $\mathrm{K}_{\mathrm{L}}$ can be plotted against the concentration of the supernatant in the metal-containing solutions. If the Langmuir equation can be applied, the measured data should fall on a straight line with the slope giving $\mathrm{K}_{\mathrm{L}}$ and the intercept $\mathrm{K}_{\mathrm{L}} \mathrm{b}$ values, since $1 / \mathrm{K}_{\mathrm{L}} \mathrm{b}$ is the angular and $1 / \mathrm{b}$ the linear coefficients, ${ }^{10,21}$ as represented by equation 3 .

$\left[\frac{\mathrm{C}_{\mathrm{S}}}{\mathrm{N}_{\mathrm{f}}}\right]=\left[\frac{1}{\left(\mathrm{~K}_{\mathrm{L}} \mathrm{b}\right)}\right]+\left[\frac{\mathrm{C}_{\mathrm{S}}}{\mathrm{b}}\right]$

Another fitting of the adsorption process was established by the Redlich-Peterson and Toth procedures as represented by equations 4 and 5 , respectively:

$$
\begin{aligned}
& \mathrm{N}_{\mathrm{f}}=\mathrm{K}_{\mathrm{RP}} \mathrm{bC}_{\mathrm{S}} /\left(1+\mathrm{K}_{\mathrm{RP}} \mathrm{C}_{\mathrm{S}}^{\beta}\right) \\
& \mathrm{N}_{\mathrm{f}}=\mathrm{K}_{\mathrm{T}} \mathrm{bC}_{\mathrm{S}} /\left(1+\mathrm{K}_{\mathrm{T}} \mathrm{C}_{\mathrm{S}}{ }^{\beta}\right)^{1 / \beta}
\end{aligned}
$$

where $\mathrm{K}_{\mathrm{RP}}$ and $\mathrm{K}_{\mathrm{T}}$ are constants related to adsorption capacity and $\mathrm{n}$ is an affinity constant of the adsorbent. Although equation 4 was previously employed empirically, it can be derived with the assumption of a continuous variation in thermal effect during adsorption. There is no assurance that the derivations of the Redlich-Peterson and Toth equations are unique; consequently, if the collected data can fit the equations, it is only probable, but not proven, that the surface is heterogeneous. The Redlich-Peterson and Toth models unfortunately predict both infinite adsorption at infinite concentration and a corresponding thermal effect related to the adsorption at zero coverage.

Non-linear regression was compared to obtain the optimum kinetic sorption and isothermal parameters. A trial and error procedure was employed for non-linear methods using the solver add-in functions of Microsoft Excel software. In the trial and error procedure, isotherm and kinetic parameters were determined by maximizing the coefficients of determination values. ${ }^{21}$ The least square method was used to analyze the linear form of the kinetic and isotherm models.
The coefficient of determination values $\left(r^{2}\right)$ were used in order to find the degrees of fit of the isotherm adsorption and kinetic models with the experimental data, ${ }^{22}$ as defined by equation 6 :

$$
\mathrm{r}^{2}=\frac{\Sigma\left(\mathrm{N}_{\mathrm{fCAL}}-\overline{\mathrm{N}}_{\mathrm{fEXP}}\right)^{2}}{\Sigma\left(\mathrm{N}_{\mathrm{fCAL}}-\overline{\mathrm{N}}_{\mathrm{fEXP}}\right)^{2}+\Sigma\left(\mathrm{N}_{\mathrm{fCAL}}-\mathrm{N}_{\mathrm{fEXP}}\right)^{2}}
$$

where $\mathrm{N}_{\mathrm{fEXP}}\left(\mathrm{mmol} \mathrm{g}^{-1}\right)$ is the experimental amount of divalent cation exchanged by the original and modified kaolinite samples and $\mathrm{N}_{\mathrm{fCAL}}\left(\mathrm{mmol} \mathrm{g}^{-1}\right)$ is the amount of cation obtained by kinetic isotherm models.

\section{Analytical techniques}

X-ray powder diffraction (XRD) patterns were recorded with a Philips PW 1050 diffractometer using $\mathrm{CuK}_{\alpha}$ $(0.154 \mathrm{~nm})$ radiation in the $2 \theta$ region between 2 to $65^{\circ}$ at a speed of $2^{\circ}$ per min and steps of $0.05^{\circ}$.

The samples for infrared spectroscopy were ovendried at $393 \mathrm{~K}$ to remove adsorbed water. Each sample of about $1.3 \mathrm{mg}$ was finely ground for $1 \mathrm{~min}$, combined with $100.0 \mathrm{mg}$ of oven-dried spectroscopic grade $\mathrm{KBr}$ and pressed with 7.0 ton into a disc under vacuum. The spectrum of each sample was recorded in triplicate between 400 and $4000 \mathrm{~cm}^{-1}$ by accumulating 64 scans at $4 \mathrm{~cm}^{-1}$ resolution, using a Perkin-Elmer 1760X Fourier transform infrared instrument.

BET (Brunauer-Emmett-Teller) surface areas and porosity measurements of the natural, intercalated and delaminated kaolinite samples were determined using a Quantachome/Nova Surface Area-Pore Volume Analyzer, Model 1200/5.01. The mesopore size distribution was obtained by applying the BJH (Barret-Joyner-Halenda) method to the adsorption branch of the isotherm.

The natural kaolinite $\left(\mathrm{K}_{\mathrm{NAT}}\right)$ and the intercalated $\left(\mathrm{K}_{\mathrm{UR}}\right)$ and intercalated-delaminated ( $\left.\mathrm{K}_{\mathrm{UR} / \mathrm{DL}}\right)$ forms were analyzed by inductively coupled plasma optical emission spectrometry (ICP OES), using a Perkin Elmer 3000 DV instrument. The oven-dried powdered samples weighing 231.0, 230.0 and $234.0 \mathrm{mg}$, respectively, were placed separately on weighed glass dishes and transferred quantitatively to pre-cleaned nitric acid digestion bottles. The samples were then digested with $7.0 \mathrm{~cm}^{3}$ of concentrated nitric and hydrochloric acids in 1:3 proportions in volume, with an identical volume of hydrofluoric acid over 5 days. The samples were cooled in an ice-bath and $25.0 \mathrm{~cm}^{3}$ of $0.10 \mathrm{~mol} \mathrm{dm}^{-3}$ boric acid was added with stirring, followed by $50 \mathrm{~cm}^{3}$ of deionized water, and the solution was then diluted to $100.0 \mathrm{~cm}^{3}$. For each sample, a blank and a set of elemental standards were run to calibrate the instrument. 
Transmission electron microscopy (TEM) images were recorded on a JEM 3010 URP microscope at the LNLS/ Brazil with an accelerating voltage of $300 \mathrm{kV}$. For this determination the samples were prepared by placing a drop of a suspension of particles dispersed in isopropanol onto a carbon-coated copper grid.

The samples for scanning electron microscopy (SEM) were prepared on orientated blades at $298 \pm 1 \mathrm{~K}$ and sputtered with gold. The instrument used was a model LEO-ZEISS, $430 \mathrm{Vp}$, using conditions of analysis for secondary images obtained to $20 \mathrm{kV}$, with a working distance of $11 \mathrm{~mm}$.

\section{Results and Discussion}

\section{Elemental analysis}

Elemental analyses from the ICP OES technique for the original clay sample, $\mathrm{K}_{\mathrm{NAT}}$, gave results consistent with kaolinite, with aluminum being the major component. The total mineralogical composition is given by $46.46 ; 39.42$; $0.48 ; 0.27 ; 0.26 ; 0.22$ and $0.18 \%$ of $\mathrm{SiO}_{2}, \mathrm{Al}_{2} \mathrm{O}_{3}, \mathrm{Fe}_{2} \mathrm{O}_{3}$, $\mathrm{MgO}, \mathrm{Na}_{2} \mathrm{O}, \mathrm{CaO}$ and $\mathrm{K}_{2} \mathrm{O}$, respectively, and $12.63 \%$ of mass was lost in the ignition process.

\section{$X$-ray powder diffraction}

The determination of the total mineralogical composition of the pristine natural clay sample was carried out on oriented mounts, exhibiting mainly kaolinite, quartz and goethite, besides the existence of mica in low concentration, as shown in Figure 1a, in agreement with the elemental analysis. These considerations are based on chemical analyses and characteristics X-ray diffraction (XRD) peaks of these minerals. ${ }^{4}$

From diffraction patterns, the $\mathrm{d}_{001}$ values were determined and the results are listed in Table 1. After the intercalation process the kaolinite presented, as expected, an increase in the basal distance, changing the $d_{001}$ value from $0.72 \mathrm{~nm}$ for natural kaolinite to $1.08 \mathrm{~nm}$ for the intercalated form, as shown in Figures $1 \mathrm{Aa}$ and $1 \mathrm{Ab}$. It was also observed that the $\mathrm{K}_{\mathrm{NAT}}$ sample presents a slightly broader and less intense peak, in comparison with $\mathrm{K}_{\mathrm{UR}}$, a behavior that could be attributed to differences in the degree of crystallinity, which was calculated by using the Biscaye equation, ${ }^{8}$ as listed in Table 1 , due to the effect of urea insertion, to give 0.90 and 0.88 for the natural and intercalated forms. The delaminated clay sample gave characteristics of a collapsed structure and low crystallinity, as shown in Figure 1Ac, which suggested the clear influence of the delamination process on the kaolinite structure. The natural kaolinite and its intercalated form, in expanded scale in part B of Figure 1Bb, presents the new peak with $\mathrm{d}_{001}$ at $1.27 \mathrm{~nm}$ that is attributed to urea interaction
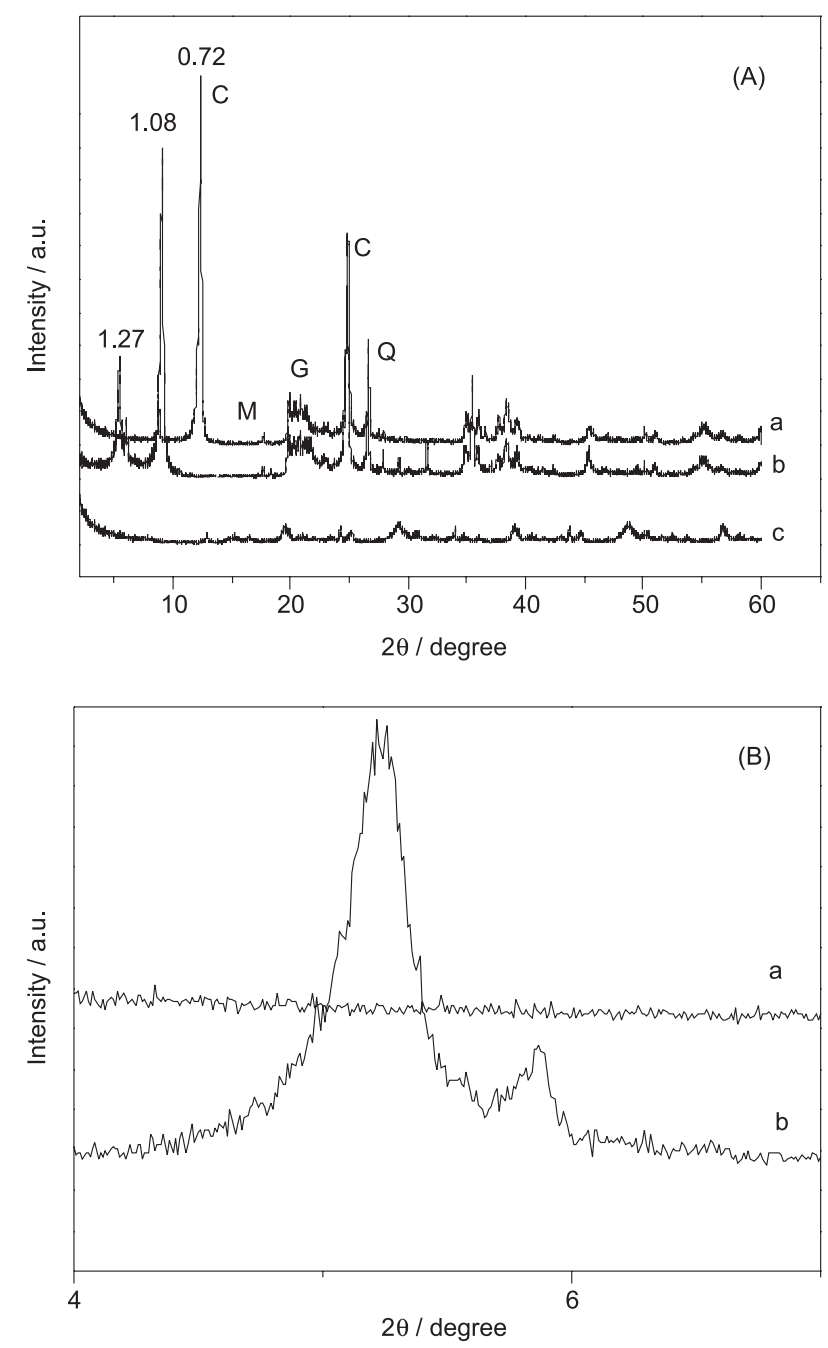

Figure 1. A: $X$-ray diffraction patterns for samples of (a) natural kaolinite (C), goethite $(\mathrm{G})$, quartz $(\mathrm{Q})$ and mica $(\mathrm{M})$, (b) $\mathrm{K}_{\mathrm{UR}}$ and (c) $\mathrm{K}_{\mathrm{UR} / \mathrm{DL}}$. B: Detail of patterns for natural kaolinite and $\mathrm{K}_{\mathrm{UR}}$ from 4 to $11^{\circ}$ for (a) and (b).

Table 1. Basal spacing $\left(\mathrm{d}_{001}\right)$, surface area $(\mathrm{S})$, micropore area $(\mathrm{Ma})$, crystallinity $(\mathrm{Cr})$, pore volume $(\mathrm{P})$ and pore diameter $(\mathrm{PD})$ for natural $\left(\mathrm{K}_{\mathrm{NAT}}\right)$, intercalated $\left(\mathrm{K}_{\mathrm{UR}}\right)$ and delaminated $\left(\mathrm{K}_{\mathrm{UR} / \mathrm{DL}}\right)$ kaolinite samples

\begin{tabular}{lcccccc}
\hline Sample & $\mathrm{d}_{001} / \mathrm{nm}$ & $\mathrm{S} /\left(\mathrm{m}^{2} \mathrm{~g}^{-1}\right)$ & $\mathrm{Ma} /\left(\mathrm{m}^{2} \mathrm{~g}^{-1}\right)$ & $\mathrm{Cr}$ & $\mathrm{P} /\left(\mathrm{cm}^{3} \mathrm{~g}^{-1}\right)$ & $\mathrm{PD} / \mathrm{nm}$ \\
\hline $\mathrm{K}_{\mathrm{NAT}}$ & 0.72 & 20.3 & 8.21 & 0.90 & 3.54 & 0.12 \\
$\mathrm{~K}_{\mathrm{UR}}$ & 1.08 & 44.5 & 9.11 & 0.88 & 3.90 & 0.20 \\
$\mathrm{~K}_{\mathrm{UR} / \mathrm{DL}}$ & - & 90.5 & 22.98 & - & 8.75 & 0.75 \\
\hline
\end{tabular}


inside the kaolinite layer. When hydrated kaolinite was intercalated with $20 \%$ urea and washed with water under ultrasound, a distance of $0.84 \mathrm{~nm}$ was obtained. ${ }^{14}$ The $\mathrm{d}_{001}$ values for the delaminated kaolinite are in agreement with previous results. ${ }^{15,16}$

\section{Infrared spectroscopy}

The Fourier-transform infrared spectra of the natural kaolinite $\mathrm{K}_{\mathrm{NAT}}$, intercalated $\mathrm{K}_{\mathrm{UR}}$ and the delaminated form $\mathrm{K}_{\mathrm{UR} / \mathrm{DL}}$ are shown in Figure 2. The original $\mathrm{K}_{\mathrm{NAT}}$ sample exhibited all characteristic hydroxyl stretching bands ${ }^{5}$ attributed to the inner-surface hydroxyls oriented towards the interlayer at $3695 \mathrm{~cm}^{-1}$. The bands at 3622 and $3463 \mathrm{~cm}^{-1}$ are assigned to those hydroxyl groups oriented towards the vacant sites in the external layers of the kaolinite structure. ${ }^{6}$ Additional weak, broad bands of kaolinite at $3463 \mathrm{~cm}^{-1}$ and another weak one at $1639 \mathrm{~cm}^{-1}$ can be associated with water adsorbed on the external surface. ${ }^{14}$

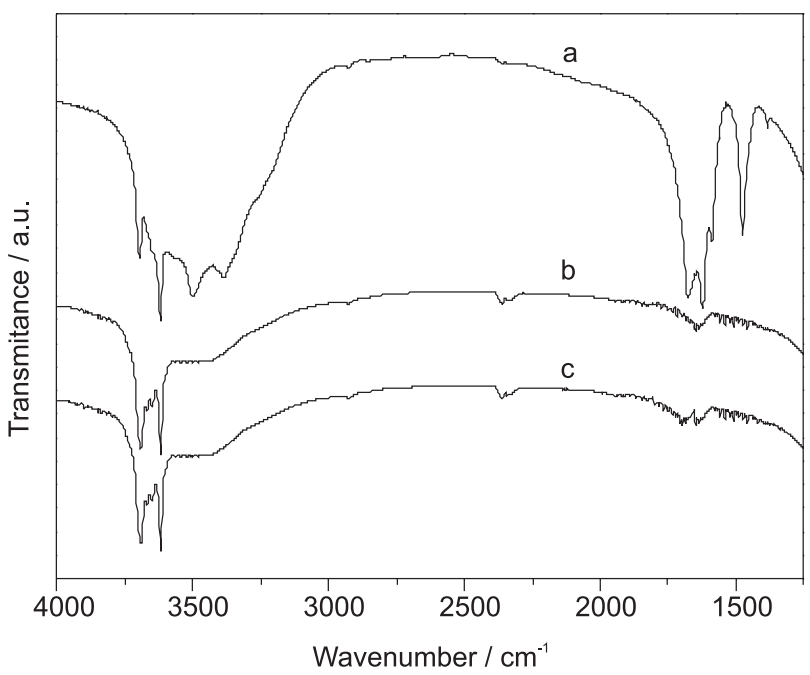

Figure 2. FTIR spectra of the kaolinite samples, $\mathrm{K}_{\mathrm{UR}}(\mathrm{a}), \mathrm{K}_{\mathrm{NAT}}$ (b) and $\mathrm{K}_{\mathrm{UR} / \mathrm{DL}}(\mathrm{c})$.

The spectrum of the intercalated material presented a similar set of frequencies for hydroxyl vibrations as does natural $\mathrm{K}_{\mathrm{NAT}}$, which is in agreement with other kaoliniteurea complexes. ${ }^{14}$ The bands located at 3505, 1683 and $1463 \mathrm{~cm}^{-1}$ were assigned to $\mathrm{N}-\mathrm{H}, \mathrm{C}=\mathrm{O}$ and $\mathrm{C}-\mathrm{N}$ stretching vibrations, respectively. The band at $3505 \mathrm{~cm}^{-1}$ is attributed to the formation of a hydrogen bond between the $\mathrm{NH}_{2}$ urea group and oxygen atoms from the basal tetrahedral sheet. ${ }^{17}$ The intercalated $\mathrm{K}_{\mathrm{UR}}$ displayed characteristic hydroxyl stretching bands at 3670 and $3650 \mathrm{~cm}^{-1}$, but with reduced intensity and strongly broadened. This behavior may be attributed to the loss of hydrogen bonding of the outer hydroxyls between the layers. In addition, there are two new sets of weak bands: (i) the formation of hydrogen bonds between $\mathrm{NH}_{2}$ urea groups and $\mathrm{O}-\mathrm{Si}-\mathrm{O}$ groups of kaolinite in the 3381 to $3505 \mathrm{~cm}^{-1}$ interval and (ii) the symmetric and asymmetric vibrational modes of $\mathrm{NH}_{2}$ urea groups that interact with oxygen atoms of the $\mathrm{Si}_{2} \mathrm{O}_{5}$ layers in the 3204 to $3413 \mathrm{~cm}^{-1}$ region. ${ }^{17}$ The $\mathrm{C}=\mathrm{O}$ stretching vibration of the urea molecule is also observed at $1683 \mathrm{~cm}^{-1}$ for the intercalated urea-kaolinite, as observed before. ${ }^{18}$

\section{Textural analysis}

The gaseous nitrogen adsorption values for natural, intercalated and delaminated kaolinite samples are listed in Table 1. The nitrogen BET data was used to calculate the specific surface areas for comparative purposes. The BET surface areas of the kaolinite samples demonstrated that intercalation and delamination processes caused the formation of mesopores in the solid particles, resulting in a higher surface area, $90.5 \mathrm{~m}^{2} \mathrm{~g}^{-1}$, relative to the natural sample, $\mathrm{K}_{\mathrm{NAT}}$, with $20.3 \mathrm{~m}^{2} \mathrm{~g}^{-1}$. The pore size distribution in the mesopores region was obtained by applying the $\mathrm{BJH}$ method from the nitrogen isotherms at $77 \mathrm{~K}$. The pore size distribution was compared by considering natural and intercalated samples, as shown in Figure 3. The natural kaolinite sample exhibited a pore volume of $3.54 \mathrm{~cm}^{3} \mathrm{~g}^{-1}$, while the intercalated and delaminated kaolinites gave values of $3.90 \mathrm{~cm}^{3} \mathrm{~g}^{-1}$ and $8.75 \mathrm{~cm}^{3} \mathrm{~g}^{-1}$ respectively. The $\mathrm{K}_{\mathrm{UR}}$ and $\mathrm{K}_{\mathrm{UR} / \mathrm{DL}}$ samples presented a unimodal distribution of pore sizes, while $\mathrm{K}_{\mathrm{NAT}}$ has a bimodal distribution. The present values of surface areas are in agreement with those reported before in the 5 to $25 \mathrm{~m}^{2} \mathrm{~g}^{-1}$ interval for kaolinite, ${ }^{24}$ which depends on particle size distribution, particle shape, and distribution of cracks and pores in the material, and therefore, cannot be represented as a general characteristic of a particular type of material. ${ }^{25}$

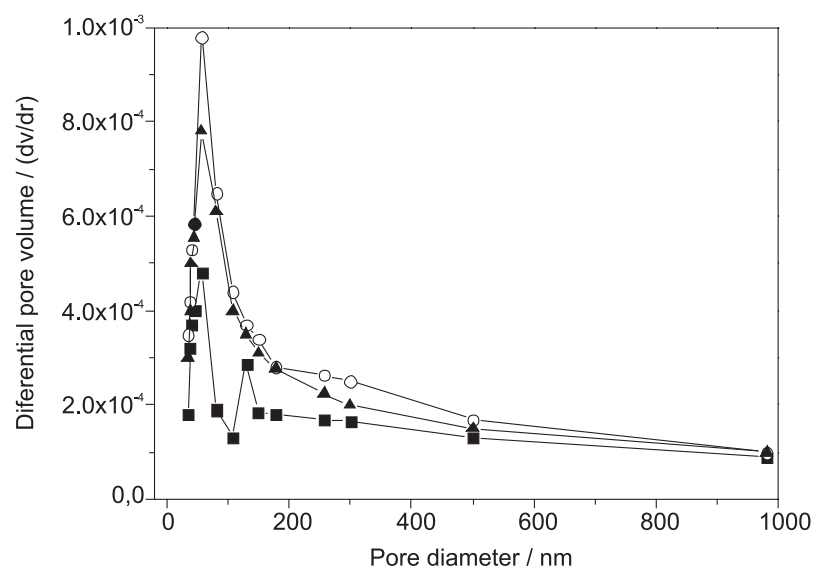

Figure 3. Pore size distribution curves of natural and modified kaolinite samples: $\mathrm{K}_{\mathrm{NAT}}(\boldsymbol{\square}), \mathrm{K}_{\mathrm{UR}}(\bigcirc)$ and $\mathrm{K}_{\mathrm{UR} / \mathrm{DL}}(\boldsymbol{\Delta})$. 


\section{Microscopy}

The TEM and SEM images were obtained in parallel position related to the layers, in 010 or 100 planes, as shown in Figures 4 and 5, respectively. The images for natural and delaminated kaolinites in the 001 plane are shown in Figures $4 \mathrm{a}$ and $4 \mathrm{~b}$, respectively. The individual crystals presented themselves as flakes in a pseudo-hexagonal form, as confirmed by TEM images, and the delaminated kaolinite structure is shown in Figure 4b. The reduction of particle size after the delamination process is shown in the TEM image, where the separation and disintegration into small stacks of flakes is clear, in comparison with Figure $4 \mathrm{a}$, which could be attributed to the use of ultrasonic procedure.

SEM images were used to probe the changes in the morphological features of $\mathrm{K}_{\mathrm{NAT}}$ and $\mathrm{K}_{\mathrm{UR} / \mathrm{DL}}$ samples, as shown in Figures $5 \mathrm{a}$ and $5 \mathrm{~b}$, respectively. The surface morphology of a natural sample presents corn-flake like crystals with a cottony appearance, revealing its extremely fine plate-like structure, Figure 5a. However, after intercalation, the clay becomes more porous and

a)

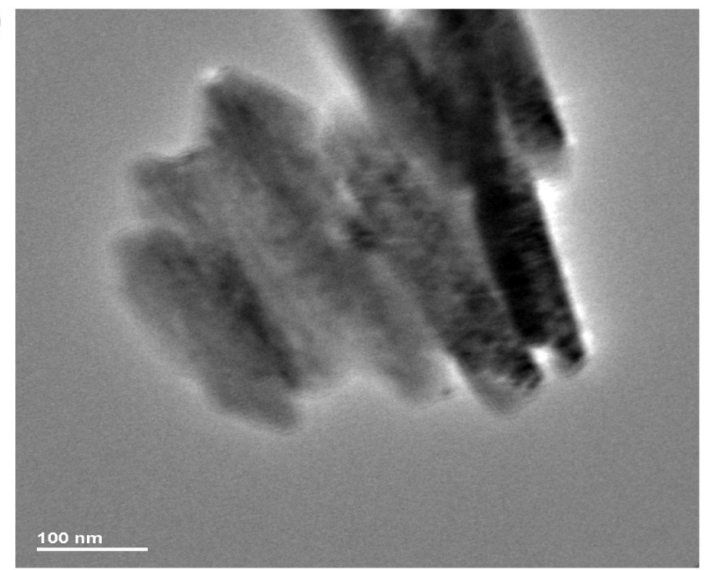

fluffy, Figure 5b. This appearance is probably due to the change in the surface charge of the particle, as a result of the intercalation process, and the reduction in amorphous phase originally associated with the natural clay sample. However, both samples present thick stacks with thin single flakes, as are observed for other chemically modified kaolinites. This texture is not consistent with the propensity of $\mathrm{K}_{\mathrm{UR} / \mathrm{DL}}$ to convert spontaneously into individual flakes or small stacks of pseudo-hexagonal flakes as shown in Figure 5b.

\section{Effect of $p H$}

The $\mathrm{pH}$ of the aqueous solution, which increased almost linearly up to $\mathrm{pH} 5.0$, is an important controlling parameter in the adsorption process. Both the extent of adsorption and the amount adsorbed $\left(\mathrm{N}_{\mathrm{f}}\right)$ showed positive changes. The influence of the $\mathrm{pH}$ on the concentration adsorbed for natural and modified kaolinites is shown in Figure 6, demonstrating that the cation exchanges strongly as the acidity of the solution decreases. The adsorption experiments at $\mathrm{pH}$ values higher that 5.0 were not carried out due to the risks of cation hydrolysis. ${ }^{21}$

b)

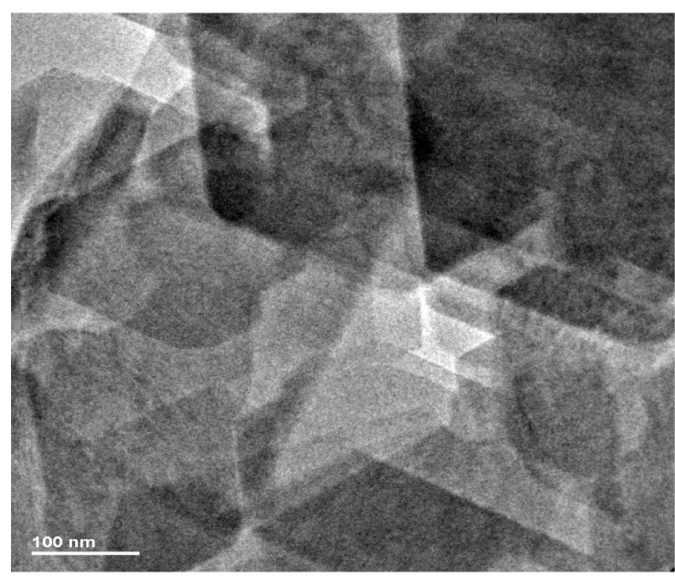

Figure 4. TEM of natural- $\mathrm{K}_{\mathrm{NAT}}$ (a) and modified kaolinite- $\mathrm{K}_{\mathrm{UR} / \mathrm{DL}}$ (b) samples.
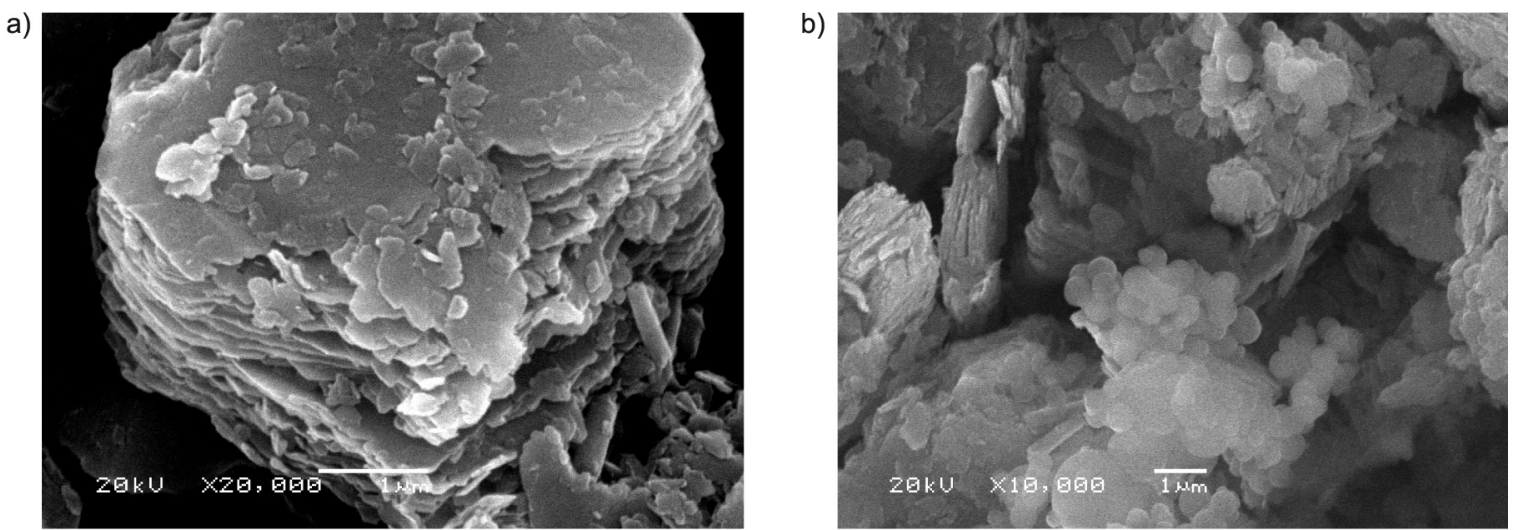

Figure 5. SEM of natural- $\mathrm{K}_{\mathrm{NAT}}$ (a) and modified kaolinite- $\mathrm{K}_{\mathrm{UR/DL}}$ (b) samples. 

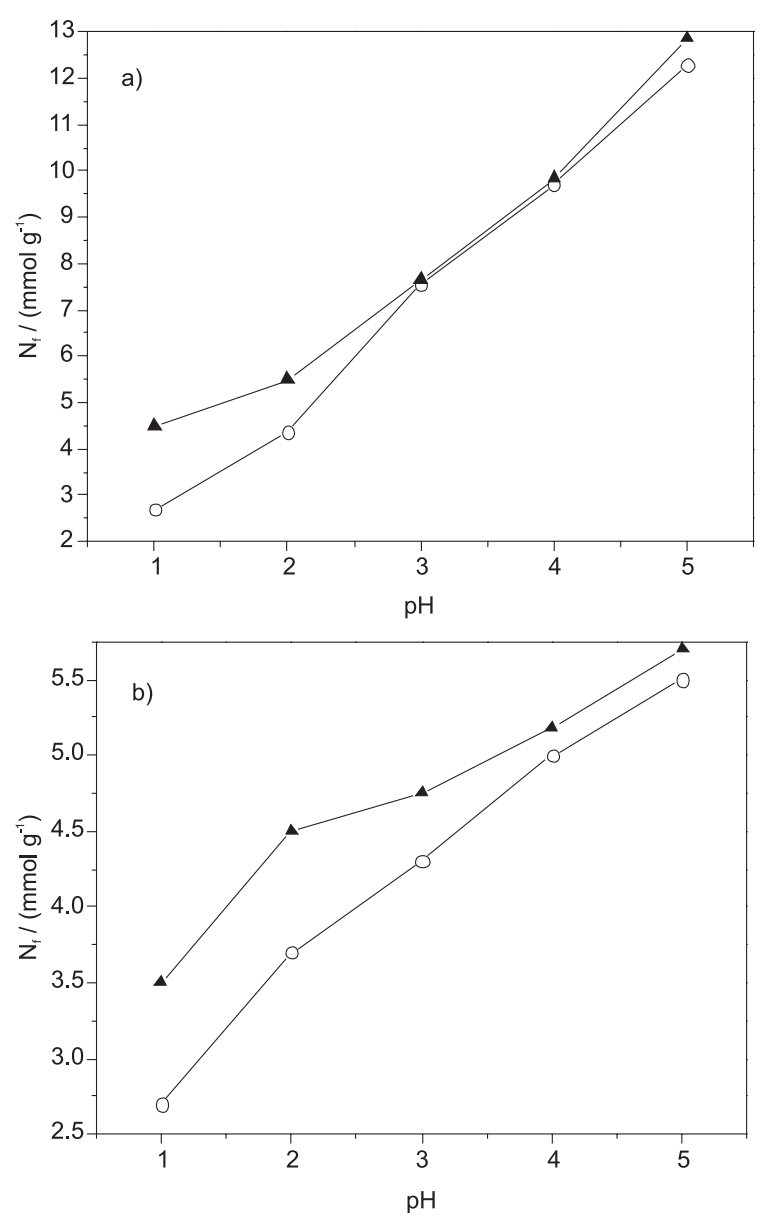

Figure 6. Effect of $\mathrm{pH}$ on cation adsorption from aqueous solution for $2.0 \mathrm{mg} \mathrm{dm}^{-3}$ clay, with copper(II) at $12.08 \mathrm{mg} \mathrm{dm}^{-3}$ and lead(II) at $14.62 \mathrm{mg} \mathrm{dm}^{-3}$, at $298 \pm 1 \mathrm{~K}$ for: $\mathrm{K}_{\mathrm{UR} / \mathrm{DL}}$ (a) and $\mathrm{K}_{\mathrm{NAT}}$ (b) with $\mathrm{Cu}(\mathrm{O})$ and $\mathrm{Pb}(\mathbf{\Delta})$.

For a strongly acidic medium, the proton concentration outnumbers the lead ions in the adsorptive solution. Thus, and it is expected that, at low $\mathrm{pH}$, the adsorptive sites will be covered by protons. By increasing the $\mathrm{pH}$, the surface sites become free for adsorption of the various lead species. Similar observations have already been reported for lead in natural and chemically modified clay adsorption processes. ${ }^{19}$

The number of available hydrogen ions is high at low $\mathrm{pH}$ values and copper cations must compete with them to exchange all adsorption sites on the inorganic surface. These active sites on the adsorbent surface are gradually deprotonated with the increase in $\mathrm{pH}$, favoring copper uptake, with an adsorption mechanism similar to that previously reported. ${ }^{1-3}$

\section{Cation adsorption}

Adsorption processes involve an array of phenomena that can alter the distribution of undesirable agents on the constituent phases and interfaces of a given system. ${ }^{20}$ Thus,
Table 2. The maximum adsorption capacity, $\mathrm{N}_{\mathrm{f}}^{\max }$, for each metal on natural, $\mathrm{K}_{\mathrm{NAT}}$ and modified kaolinites, $\mathrm{K}_{\mathrm{UR}}, \mathrm{K}_{\mathrm{UR} / \mathrm{DL}}$

\begin{tabular}{lccc}
\hline $\mathrm{M}^{2+}$ & $\mathrm{K}_{\mathrm{NAT}}$ & $\mathrm{K}_{\mathrm{UR}}$ & $\mathrm{K}_{\mathrm{UR} / \mathrm{DL}}$ \\
\hline $\mathrm{Cu}^{2+}$ & $5.0 \pm 0.2$ & $7.5 \pm 0.1$ & $12.3 \pm 0.2$ \\
$\mathrm{~Pb}^{2+}$ & $5.6 \pm 0.2$ & $11.3 \pm 0.2$ & $12.8 \pm 0.2$ \\
\hline
\end{tabular}

Clay, $3.0 \mathrm{~g} \mathrm{dm}^{-3}$; initial $\mathrm{Cu}^{2+}, 12.08 \mathrm{~g} \mathrm{dm}^{-3}$; initial $\mathrm{Pb}^{2+}, 14.62 \mathrm{~g} \mathrm{dm}^{-3}$; controlled temperature, $298 \pm 1 \mathrm{~K} ; \mathrm{pH}=5.0$.

adsorption at a surface or interface is mainly a result of binding forces between the individual atoms, molecules or ions of the adsorbate to the surface, all of these forces having some electrostatic effects to promote interaction. ${ }^{21}$ Divalent cations $\left(\mathrm{M}^{2+}\right)$ can be adsorbed on the available surface sites, denoted by $\equiv \mathrm{SOH}$, where $\mathrm{S}$ represents silicon or aluminum atoms in the inorganic structure, these atoms being main elements in the clay composition, as listed in Table 2. For this process, the reactive edge sites $(\mathrm{OH}$ and $\mathrm{NH}_{2}$ groups) on the surface can interact with cations in solution, as given by equations 7 to 9 :

$\equiv \mathrm{SOH}+\mathrm{M}^{2+} \rightleftharpoons \equiv \mathrm{SOM}^{+}+\mathrm{H}^{+}$,

$\equiv \mathrm{SOH}+\mathrm{M}^{2+}+\mathrm{H}_{2} \mathrm{O} \rightleftharpoons \equiv \mathrm{SOMOH}+2 \mathrm{H}^{+}$,

$2 \equiv \mathrm{SOH}+\mathrm{M}^{2+} \rightleftharpoons \equiv \mathrm{SO}_{2} \mathrm{M}+2 \mathrm{H}^{+}$.

On the surface sites the original $\equiv \mathrm{SOH}$ group can exchange with cations $\left(\mathrm{M}^{2+}\right)$, as represented in equations 10 and 11:

$2 \equiv \mathrm{SOH}+\mathrm{M}^{2+} \rightleftharpoons \equiv \mathrm{SO}_{2} \mathrm{M}+2 \mathrm{H}^{+}$,

$\equiv \mathrm{SOH}+\mathrm{M}^{2+}+\mathrm{H}_{2} \mathrm{O} \rightleftharpoons \equiv \mathrm{SOMOH}+2 \mathrm{H}^{+}$.

During the course of the adsorption the inner-sphere interactive process is predominant over that of the outersphere for divalent metal cations adsorbed by edge sites. ${ }^{20}$ Both cations presented similar isotherms with kaolinite and its intercalated and delaminated forms, as exemplified for copper in Figure 7 and lead in Figure 8. As observed, for the matrix containing urea, the adsorption amounts are higher at the saturation isotherm plateau. The maximum adsorption capacities, $\mathrm{N}_{\mathrm{f}}^{\max }$, for each metal on natural and modified kaolinites are listed in Table 2. The adsorptions are higher for modified matrices.

These results were adjusted to fit the Langmuir, RedlichPeterson and Toth models, as listed in Table 3, and the linear and nonlinear correlation adjustments from these equations are shown in Figure 9. All three adsorption models can be used to explain the significant adsorptive capacity of the intercalated matrix and to quantify copper and lead 


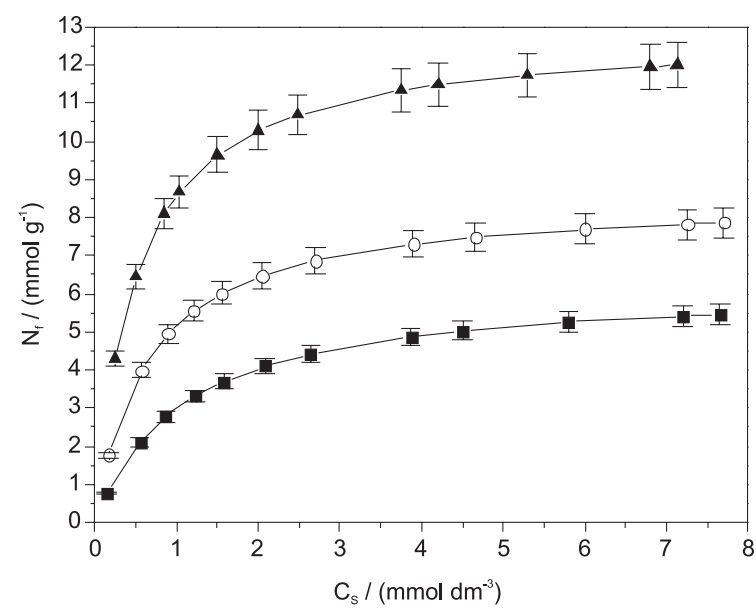

Figure 7. Experimental data for copper adsorption by kaolinite samples, using $2.0 \mathrm{~g} \mathrm{dm}^{-3}$ clay; copper(II) concentration $12.08 \mathrm{mg} \mathrm{dm}^{-3} ; 298 \pm 1 \mathrm{~K}$ at pH 5.0 for $\mathrm{K}_{\mathrm{NAT}}(\boldsymbol{\square}), \mathrm{K}_{\mathrm{UR}}(\mathrm{O})$ and $\mathrm{K}_{\mathrm{UR} / \mathrm{DL}}(\boldsymbol{\Delta})$.

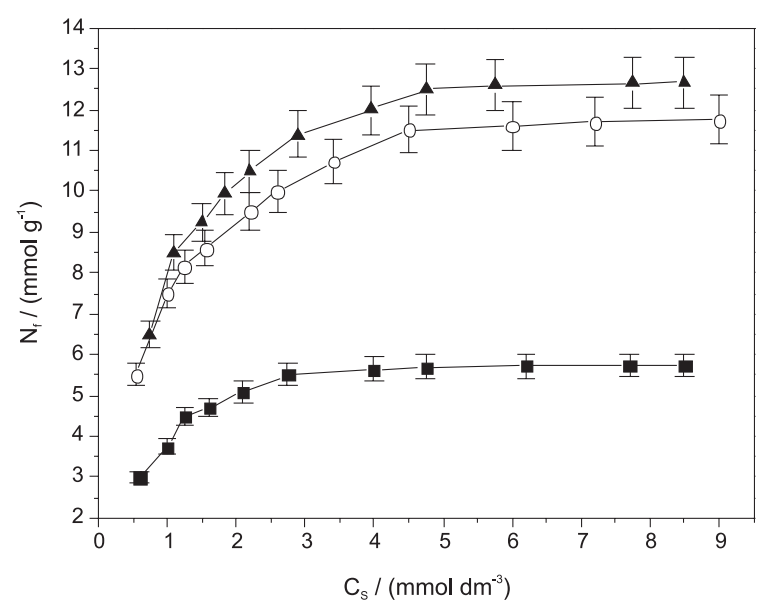

Figure 8. Experimental data for lead adsorption by kaolinite samples, using $2.0 \mathrm{~g} \mathrm{dm}^{-3}$ clay; lead(II) concentration $12.08 \mathrm{mg} \mathrm{dm}^{-3}$ at $\mathrm{pH} 5.0$; $298 \pm 1 \mathrm{~K}$ for $\mathrm{K}_{\mathrm{NAT}}(\mathbf{\square}), \mathrm{K}_{\mathrm{UR}}(\mathrm{O})$ and $\mathrm{K}_{\mathrm{UR} / \mathrm{DL}}(\mathbf{\Delta})$.

interactions with these inorganic matrices, although the Langmuir model presents a significant advantage in comparison with the others. It allows the quantification of the capacity of cations in the structure of the matrix and the evaluation of the constant related to the binding energy.

The interaction of these cations with the intercalated surfaces of the kaolinite structure is governed by the microenvironment around each arrangement, which is usually composed of basic centers, mainly in the internal structure of hydration. Hydroxyl groups act as bridges that result in the kaolinite matrix intercalation process.

\section{Kinetic processes}

Pseudo-first order kinetics using the Lagergren equation $^{26-38}$ is generally expressed by equation 12 : $\frac{\partial \mathrm{N}_{\mathrm{t}}}{\partial \mathrm{t}}=\mathrm{k}_{1}\left(\mathrm{~N}_{\mathrm{fEQ}}-\mathrm{N}_{\mathrm{f}}\right)$

After integration and applying the boundary conditions, $N_{t}=0$ for $t=0$ and $N_{t}=N_{t}$ at $t=t$, the integrated form of equation 12 becomes:

$\ln \left(\mathrm{N}_{\mathrm{fEQ}}-\mathrm{N}_{\mathrm{f}}\right)=\ln \mathrm{N}_{\mathrm{fEQ}}-\mathrm{k}_{1} \mathrm{t}$

where $\mathrm{N}_{\mathrm{fEQ}}$ and $\mathrm{N}_{\mathrm{f}}$ are the amounts of metal adsorbed at equilibrium and at a given time $\mathrm{t}\left(\mathrm{mmol} \mathrm{g}^{-1}\right)$, respectively, and $\mathrm{k}_{1}$ is the rate constant for pseudo-first order adsorption $\left(\mathrm{min}^{-1}\right)$.

When the rate of reaction of an adsorption reaction is controlled by chemical exchange, then a pseudo-second order model can be better adjusted to the experimental kinetic data, ${ }^{26-39}$ as expressed by equation 14 .

$\frac{\partial \mathrm{N}_{\mathrm{f}}}{\partial \mathrm{t}}=\mathrm{k}_{2}\left(\mathrm{~N}_{\mathrm{fEQ}}-\mathrm{N}_{\mathrm{f}}\right)^{2}$

After integration and applying the boundary conditions, $N_{t}=0$ for $t=0$ and $N_{t}=N_{t}$ at $t=t$, the integrated form of equation 14 becomes:

$\frac{\mathrm{t}}{\mathrm{N}_{\mathrm{f}}}=\left(\frac{1}{\mathrm{k}_{2} \mathrm{~N}_{\mathrm{fEQ}}^{2}}\right)+\left(\frac{1}{\mathrm{~N}_{\mathrm{fEQ}}}\right) \mathrm{t}$

where $\mathrm{k}_{2}$ is the pseudo-second order rate $\left(\mathrm{mmol}^{-1} \mathrm{~min}^{-1}\right)$. The values of $\mathrm{k}_{2}$ can be obtained from the $y$-intercept of the linear plot of $\mathrm{t} / \mathrm{N}_{\mathrm{f}}$ versus $\mathrm{t}$.

Carrying out a set of experiments at constant temperature and monitoring the amount adsorbed with time, the kinetics of the adsorption process should be known. The adsorption using the Lagergren model can also be explored, ${ }^{26-38}$ as proposed in equation 12 .

The useful Elovich equation for energetically heterogeneous solid surfaces is represented by equations 16 and 17 in nonlinear and linear ${ }^{1}$ forms, respectively:

$\mathrm{N}_{\mathrm{f}}=\ln (\alpha \beta \mathrm{t})^{\beta}$

$\mathrm{N}_{\mathrm{f}}=\beta \ln (\alpha \beta)+\beta \ln \mathrm{t}$

where $\alpha$ and $\beta$, the Elovich coefficients, represent the initial adsorption rate $\left(\mathrm{mmol} \mathrm{g}^{-1} \mathrm{~min}^{-1}\right)$ and the desorption coefficient $\left(\mathrm{g} \mathrm{mmol}^{-1}\right)$, respectively.

The modified and natural kaolinites showed identical behavior towards copper and lead uptake with increasing interaction time at $\mathrm{pH}$ 5.0. Adsorption increased rapidly up to $1 \mathrm{~h}$ and slowly increased as equilibrium was reached, as shown in Figure 10. The lead uptake became almost 
Table 3. Parameters from Langmuir, Redlich-Peterson and Toth equations for metal adsorption on natural, intercalated and delaminated kaolinite samples; linear and nonlinear forms

\begin{tabular}{|c|c|c|c|c|c|c|c|c|c|}
\hline \multirow{2}{*}{$\begin{array}{l}\text { Adsorbed } \\
\mathrm{M}^{2+} \\
\end{array}$} & \multicolumn{3}{|c|}{ Langmuir } & \multicolumn{3}{|c|}{ Redlich-Peterson } & \multicolumn{3}{|c|}{ Toth } \\
\hline & $\mathrm{b}$ & $\mathrm{K}$ & $\mathrm{r}$ & $\mathrm{K}_{\mathrm{RP}}$ & $\beta$ & $\mathrm{r}$ & $\mathrm{N}$ & $\mathrm{K}_{\mathrm{T}}$ & $\mathrm{r}$ \\
\hline & & & & Linear & & & & & \\
\hline & & & & $\mathrm{K}_{\mathrm{NAT}}$ & & & & & \\
\hline $\mathrm{Cu}$ & $6.2 \pm 0.1$ & $0.8 \pm 0.3$ & 0.988 & $2.2 \pm 0.2$ & $2.3 \pm 0.1$ & 0.992 & $1.9 \pm 0.1$ & $3.7 \pm 0.2$ & 0.997 \\
\hline \multirow[t]{2}{*}{$\mathrm{Pb}$} & $6.3 \pm 0.2$ & $0.9 \pm 0.1$ & 0.999 & $2.0 \pm 0.3$ & $2.3 \pm 0.3$ & 0.998 & $1.8 \pm 0.3$ & $3.3 \pm 0.3$ & 0.996 \\
\hline & & & & $\mathrm{K}_{\mathrm{UR}}$ & & & & & \\
\hline $\mathrm{Cu}$ & $8.5 \pm 0.2$ & $1.0 \pm 0.2$ & 0.999 & 3.169 & $3.0 \pm 0.5$ & 0.985 & $2.1 \pm 0.2$ & $4.3 \pm 0.1$ & 0.997 \\
\hline \multirow[t]{2}{*}{$\mathrm{Pb}$} & $9.6 \pm 0.2$ & $1.1 \pm 0.3$ & 0.994 & 3.651 & $3.9 \pm 0.3$ & 0.987 & $2.0 \pm 0.2$ & $4.2 \pm 0.2$ & 0.996 \\
\hline & & & & $\mathrm{K}_{\mathrm{UR} / \mathrm{DL}}$ & & & & & \\
\hline $\mathrm{Cu}$ & $9.6 \pm 0.2$ & $1.0 \pm 0.3$ & 0.999 & $3.6 \pm 0.1$ & $3.1 \pm 0.5$ & 0.987 & $3.7 \pm 0.1$ & $5.6 \pm 0.3$ & 0.998 \\
\hline \multirow[t]{3}{*}{$\mathrm{Pb}$} & $9.9 \pm 0.2$ & $1.2 \pm 0.2$ & 0.998 & $4.0 \pm 0.2$ & $4.1 \pm 0.2$ & 0.998 & $4.2 \pm 0.3$ & $5.9 \pm 0.2$ & 0.998 \\
\hline & & & & Nonlinear & & & & & \\
\hline & & & & $\mathrm{K}_{\mathrm{NAT}}$ & & & & & \\
\hline $\mathrm{Cu}$ & $5.9 \pm 0.3$ & $0.9 \pm 0.1$ & 0.988 & $3.0 \pm 0.2$ & $2.4 \pm 0.2$ & 0.992 & $1.9 \pm 0.1$ & $3.7 \pm 0.2$ & 0.998 \\
\hline \multirow[t]{2}{*}{$\mathrm{Pb}$} & $6.6 \pm 0.1$ & $0.8 \pm 0.7$ & 0.999 & $3.4 \pm 0.4$ & $2.3 \pm 0.1$ & 0.998 & $1.8 \pm 0.5$ & $3.3 \pm 0.5$ & 0.997 \\
\hline & & & & $\mathrm{K}_{\mathrm{UR}}$ & & & & & \\
\hline $\mathrm{Cu}$ & $9.3 \pm 0.3$ & $0.9 \pm 0.1$ & 0.999 & $3.8 \pm 0.2$ & $2.0 \pm 0.2$ & 0.986 & $2.1 \pm 0.1$ & $4.3 \pm 0.3$ & 0.999 \\
\hline \multirow[t]{2}{*}{$\mathrm{Pb}$} & $1.0 \pm 0.1$ & $1.2 \pm 0.2$ & 0.997 & $3.7 \pm 0.1$ & $3.9 \pm 0.1$ & 0.989 & $2.1 \pm 0.3$ & $4.3 \pm 0.2$ & 0.998 \\
\hline & & & & $\mathrm{K}_{\mathrm{UR} / \mathrm{DL}}$ & & & & & \\
\hline $\mathrm{Cu}$ & $9.7 \pm 0.3$ & 0.942 & 0.999 & $3.7 \pm 0.2$ & $3.2 \pm 0.3$ & 0.998 & $3.6 \pm 0.2$ & $5.5 \pm 0.1$ & 0.999 \\
\hline $\mathrm{Pb}$ & $1.1 \pm 0.1$ & $1.2 \pm 0.3$ & 0.999 & $4.1 \pm 0.2$ & $4.1 \pm 0.1$ & 0.999 & $4.0 \pm 0.1$ & $6.0 \pm 0.2$ & 0.998 \\
\hline
\end{tabular}

Clay, $3.0 \mathrm{~g} \mathrm{dm}^{-3}$; initial $\mathrm{Cu}^{2+}, 12.08 \mathrm{~g} \mathrm{dm}^{-3}$; initial $\mathrm{Pb}^{2+}, 14.62 \mathrm{~g} \mathrm{dm}^{-3}$; controlled temperature, $298 \pm 1 \mathrm{~K} ; \mathrm{pH}=5.0$.
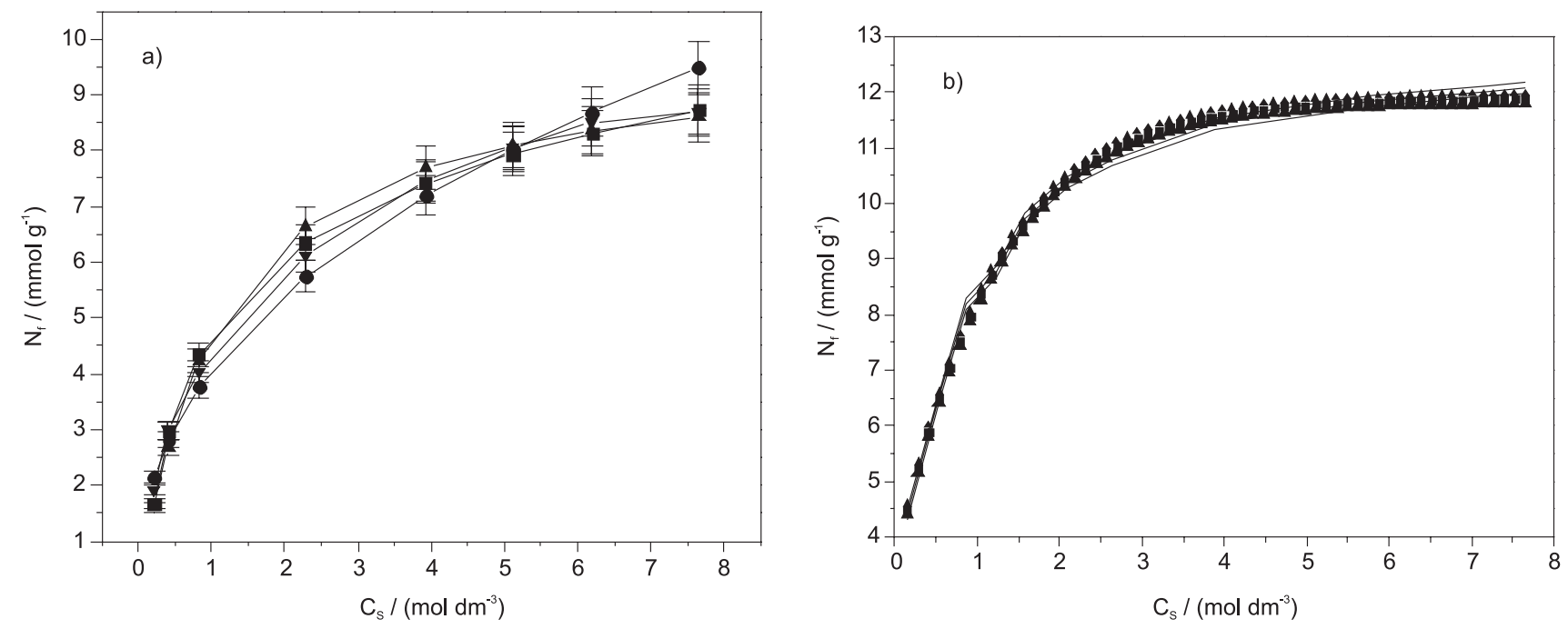

Figure 9. Experimental data fitting of lead adsorption in $\mathrm{K}_{\mathrm{UR}}$ applied to linear (a) and nonlinear of copper adsorption in $\mathrm{K}_{\mathrm{UR} / \mathrm{DL}}$ (b) models: Langmuir ( $\left.\mathbf{\Delta}\right)$, Redlich-Peterson $(\mathbf{O})$, Toth $(\boldsymbol{\square})$ models and experimental $(\boldsymbol{\nabla})$ for $2.0 \mathrm{~g} \mathrm{dm}^{-3}$ clay. Lead and copper concentrations 14.62 and $12.08 \mathrm{mg} \mathrm{dm}^{-3}$, respectively, at $\mathrm{pH}$ 5.0. 
constant after $200 \mathrm{~min}$ for natural and after $150 \mathrm{~min}$ for intercalated kaolinite samples, which can be considered reaching the equilibrium condition. The initial high rate of adsorption can be attributed to the existence the exposed

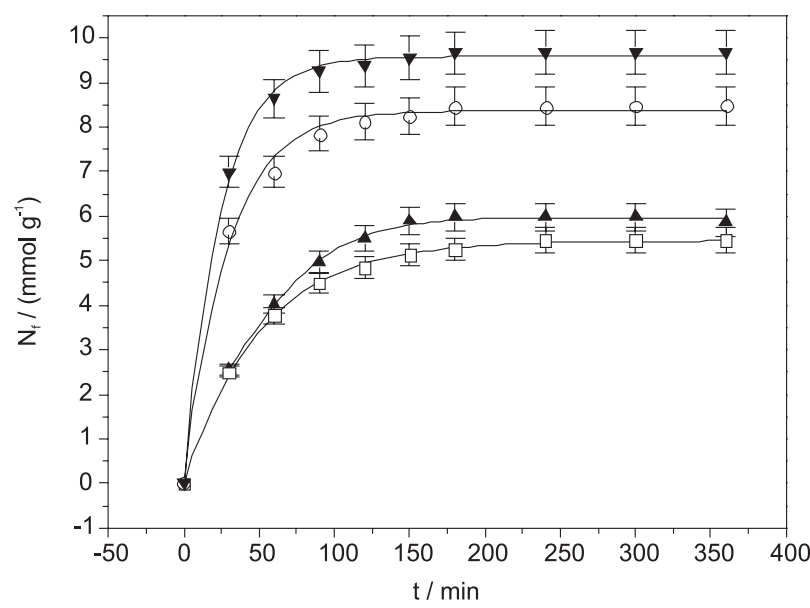

Figure 10. Adsorption isotherms of $\mathrm{K}_{\mathrm{UR}}$ and $\mathrm{K}_{\mathrm{NAT}}$ with divalent cations for $2.0 \mathrm{~g} \mathrm{dm}^{-3}$ clay, copper at 12.08 and lead at $14.62 \mathrm{mg} \mathrm{dm}^{-3}, 298 \pm 1 \mathrm{~K}$, $\mathrm{pH}$ 5.0, for $\mathrm{K}_{\mathrm{NAT}}: \mathrm{Cu}(\square), \mathrm{Pb}(\boldsymbol{\Delta})$ and $\mathrm{K}_{\mathrm{UR}}: \mathrm{Cu}(\bigcirc), \mathrm{Pb}(\boldsymbol{\nabla})$. basic centers for interaction on the readily accessible surfaces. However, as the coverage increased, the number of available surface sites for adsorption decreases until it reaches equilibrium, when the uptake is controlled by the rate at which the adsorbate is transported from the exterior to the interior sites of the adsorbent particles.

Second order kinetic plots presented better linearity with $\mathrm{R}>0.99$, and the second order rate constant, $\mathrm{k}_{2}$, varied from 4.8 to 10.9 and from 4.9 to $12.9 \mathrm{~g} \mathrm{mg}^{-1} \mathrm{~min}^{-1}$ with the linear method and from 5.0 to 11.0 and 4.9 to $13.0 \mathrm{~g} \mathrm{mg}^{-1} \mathrm{~min}^{-1}$ with the nonlinear method for copper and lead cations, respectively, as listed in Table 4. A comparison of $\mathrm{N}_{\mathrm{f}}$ experimental values and those obtained from the slopes of the second order plots showed values in the 11.40 to $2.5 \mathrm{mmol} \mathrm{g}^{-1}$ range for copper with kaolinite and lead for intercalated urea matrices with linear and nonlinear analyses, respectively, as shown in Figures 11 and 12. Considering all the above results, the kinetics of second order for cation adsorption on natural and modified kaolinites is better adjusted for both metals. ${ }^{1}$

Second order kinetics suggests that the number of adsorption sites on the clay surface and the number of

Table 4. Kinetics for pseudo-first order and pseudo-second order Lagergren and Elovich models calculated for metal adsorptions onto natural, intercalated and delaminated kaolinite samples

\begin{tabular}{|c|c|c|c|c|c|c|c|c|c|}
\hline \multirow[t]{2}{*}{ Sample } & \multicolumn{3}{|c|}{ Pseudo-first order } & \multicolumn{3}{|c|}{ Pseudo-second order } & \multicolumn{3}{|c|}{ Elovich } \\
\hline & $\begin{array}{c}\mathrm{k}_{1} \times 10^{2} / \\
\min ^{-1}\end{array}$ & $\begin{array}{c}\mathbf{N}_{\text {faal }} / \\
\left(\mathrm{mmol} \mathrm{g}^{-1}\right)\end{array}$ & $r^{2}$ & $\begin{array}{c}\mathrm{k}_{2} \times 10^{3} / \\
\left(\mathrm{mmol} \mathrm{g}^{-1} \mathrm{~min}^{-1}\right)\end{array}$ & $\begin{array}{c}\mathbf{N}_{\text {fcal }} / \\
\left(\mathrm{mmol} \mathrm{g}^{-1}\right)\end{array}$ & $\mathrm{r}^{2}$ & $\begin{array}{c}\propto \times 10^{3} / \\
\left(\mathrm{g} \mathrm{mmol}-1 \mathrm{mim}^{2}\right)\end{array}$ & $\begin{array}{c}\beta / \\
\left(\mathrm{mmol} \mathrm{g}^{-1} \mathrm{mim}^{-1}\right)\end{array}$ & $\mathrm{r}^{2}$ \\
\hline \multicolumn{10}{|c|}{ Linear } \\
\hline \multicolumn{10}{|c|}{ copper (II) } \\
\hline $\mathrm{K}_{\mathrm{NAT}}$ & $1.0 \pm 0.1$ & $4.2 \pm 0.3$ & 0.978 & $4.8 \pm 0.1$ & $6.1 \pm 0.2$ & 0.998 & $9.7 \pm 0.2$ & $1.5 \pm 0.2$ & 0.981 \\
\hline $\mathrm{K}_{\mathrm{UR}}$ & $1.1 \pm 0.2$ & $6.2 \pm 0.2$ & 0.977 & $8.9 \pm 0.3$ & $8.7 \pm 0.1$ & 0.999 & $17.4 \pm 0.2$ & $1.8 \pm 0.1$ & 0.975 \\
\hline $\mathrm{K}_{\mathrm{UR} / \mathrm{DL}}$ & $1.8 \pm 0.2$ & $7.2 \pm 0.3$ & 0.999 & $10.9 \pm 0.2$ & $9.1 \pm 0.1$ & 0.998 & $23.0 \pm 0.1$ & $2.2 \pm 0.2$ & 0.998 \\
\hline \multicolumn{10}{|c|}{ lead(II) } \\
\hline $\mathrm{K}_{\mathrm{NAT}}$ & $1.2 \pm 0.5$ & $4.7 \pm 0.5$ & 0.976 & $4.9 \pm 0.2$ & $6.3 \pm 0.2$ & 0.997 & $5,3 \pm 0.2$ & $1.2 \pm 0.1$ & 0.986 \\
\hline $\mathrm{K}_{\mathrm{UR}}$ & $1.2 \pm 0.1$ & $7.8 \pm 0.1$ & 0.977 & $11.8 \pm 0.2$ & $9.9 \pm 0.1$ & 0.998 & $18.2 \pm 0.2$ & $1.6 \pm 0.2$ & 0.976 \\
\hline$\underline{\mathrm{K}_{\mathrm{UR} / \mathrm{DL}}}$ & $2.0 \pm 0.5$ & $9.8 \pm 0.1$ & 0.998 & $12.9 \pm 0.2$ & $10.0 \pm 0.1$ & 0.998 & $25.3 \pm 0.1$ & $2.8 \pm 0.1$ & 0.998 \\
\hline \multicolumn{10}{|c|}{ Nonlinear } \\
\hline \multicolumn{10}{|c|}{ copper(II) } \\
\hline $\mathrm{K}_{\mathrm{NAT}}$ & $1.2 \pm 0.2$ & $4.1 \pm 0.2$ & 0.999 & $5.0 \pm 0.2$ & $6.1 \pm 0.1$ & 0.999 & $9.8 \pm 0.2$ & $1.5 \pm 0.2$ & 0.998 \\
\hline $\mathrm{K}_{\mathrm{UR}}$ & $1.1 \pm 0.2$ & $6.2 \pm 0.2$ & 0.998 & $8.8 \pm 0.2$ & $8.3 \pm 0.2$ & 0.999 & $18.0 \pm 0.2$ & $1.9 \pm 0.2$ & 0.998 \\
\hline $\mathrm{K}_{\mathrm{UR} / \mathrm{DL}}$ & $2.1 \pm 0.2$ & $8.9 \pm 0.5$ & 0.999 & $11.0 \pm 0.1$ & $9.1 \pm 0.1$ & 0.998 & $23.1 \pm 0.3$ & $2.3 \pm 0.2$ & 0.999 \\
\hline \multicolumn{10}{|c|}{ lead(II) } \\
\hline $\mathrm{K}_{\mathrm{NAT}}$ & $1.2 \pm 0.1$ & $4.7 \pm 0.2$ & 0.976 & $4.9 \pm 0.2$ & $6.3 \pm 0.4$ & 0.999 & $5,3 \pm 0.2$ & $1.2 \pm 0.1$ & 0.986 \\
\hline $\mathrm{K}_{\mathrm{UR}}$ & $1.4 \pm 0.2$ & $7.8 \pm 0.3$ & 0.997 & $11.8 \pm 0.2$ & $10.0 \pm 0.2$ & 0.998 & $18.2 \pm 0.1$ & $1.6 \pm 0.3$ & 0.996 \\
\hline $\mathrm{K}_{\mathrm{UR} / \mathrm{DL}}$ & $2.1 \pm 0.5$ & $10.2 \pm 0.4$ & 0.989 & $13.0 \pm 0.2$ & $11.0 \pm 0.2$ & 0.999 & $25.5 \pm 0.3$ & $2.7 \pm 0.1$ & 0.999 \\
\hline
\end{tabular}

Clay, $3.0 \mathrm{~g} \mathrm{dm}^{-3}$; initial $\mathrm{Cu}^{2+}, 12.08 \mathrm{~g} \mathrm{dm}^{-3}$; initial $\mathrm{Pb}^{2+}, 14.62 \mathrm{~g} \mathrm{dm}^{-3}$; controlled temperature, $298 \pm 1 \mathrm{~K} ; \mathrm{pH}=5.0$; time, $360 \mathrm{~min}$. 
heavy metal cations in the liquid phase together determine the kinetics. Depending on $\mathrm{pH}$, different cationic species may be held to the clay surface at appropriate ion-exchange sites. $^{27}$
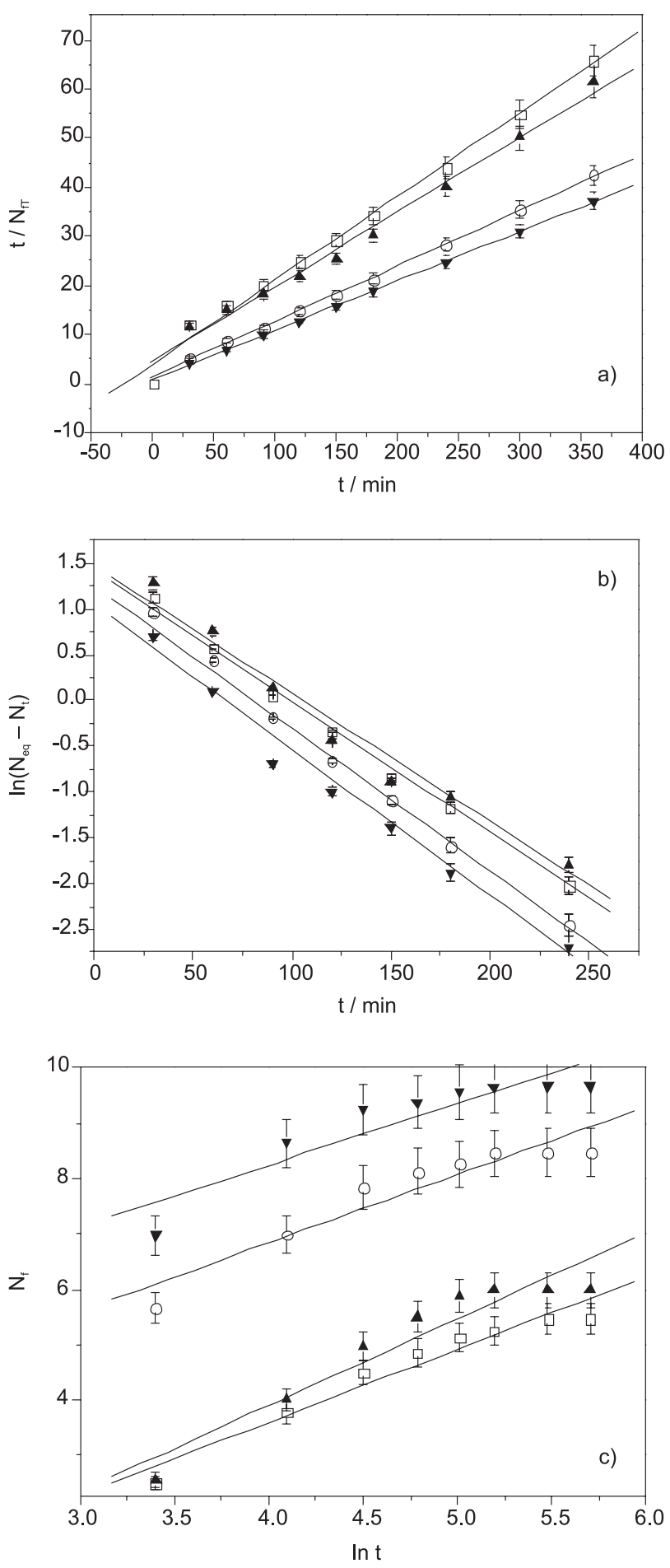

Figure 11. Linearization of adsorption isotherms obtained by kinetic models: (a) pseudo-second order; (b) pseudo-first order and (c) Elovich equation. Clay: $2.0 \mathrm{~g} \mathrm{dm}^{-3}$; divalent copper at 12.08 and lead at $14.62 \mathrm{mg} \mathrm{dm}^{-3} ; 298 \pm 1 \mathrm{~K}, \mathrm{pH} 5.0$, time $360 \mathrm{~min} . \mathrm{K}_{\mathrm{NAT}}$ : $\mathrm{Cu}(\square), \mathrm{Pb}(\mathbf{\Delta})$; $\mathrm{K}_{\mathrm{UR}}: \mathrm{Cu}(\bigcirc), \mathrm{Pb}(\boldsymbol{\nabla})$.

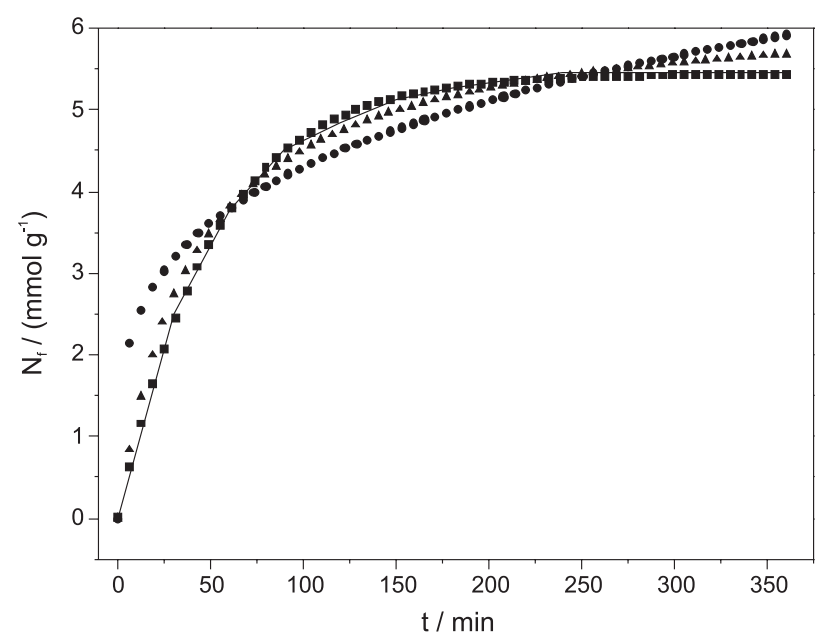

Figure 12. The experimental fitting of lead adsorption data applied to nonlinear models: Elovich $(\bullet)$, Lagergren pseudo-first order $(\boldsymbol{\Delta})$, pseudosecond order models ( $)$ and experimental (一) for $2.0 \mathrm{~g} \mathrm{dm}^{-3}$ clay. Lead concentration $14.62 \mathrm{mg} \mathrm{dm}^{-3}$ at $\mathrm{pH}$ 5.0.

\section{Conclusions}

Synthesized urea-intercalated kaolinite, originally from the Perus region, Brazil, has high stability, into which active basic sites can be introduced, improving the physicalchemical properties of the precursor clay. For example, the specific area of the original kaolinite, $20.3 \mathrm{~m}^{2} \mathrm{~g}^{-1}$, changed after intercalation and delamination to 44.5 and $90.5 \mathrm{~m}^{2} \mathrm{~g}^{-1}$, respectively. Identically, the modified clays, when applied to the metal adsorption process, increased their capacities for divalent lead and copper removal, a favorable condition attributed to the available edge sites on the inorganic backbone, to give the order $\mathrm{Pb}>\mathrm{Cu}$.

Adsorption either on natural or intercalated clays increased continuously with $\mathrm{pH}$, by limiting the hydrolysis of both cations and $\mathrm{NH}_{2}$ anchored in the kaolinite surface. The most appropriate condition was chosen to be $\mathrm{pH} 5.0$ at room temperature, presenting a plateau at 200 and $150 \mathrm{~min}$ for natural and modified kaolinites, respectively. The copper and lead cations showed very rapid initial uptakes on both inorganic supports before reaching the plateau. Langmuir, Redlich-Peterson and Toth isotherms yielded good fits with the adsorption data for cation/clay interactions.

The kinetics of adsorption of both heavy metals used in this investigation on natural, intercalated and delaminated kaolinites were complex, but it seems that this interactive effect is better expressed by a pseudosecond order process. Linear and nonlinear regression methods were compared to evaluate the experimental data with a pseudo-second order kinetic model. Non-linear regression exhibited a higher coefficient of determination for the isotherm and the kinetic analyses than a linear regression. 


\section{Acknowledgments}

The authors are indebted to CNPq for fellowships and financial support, and LNLS from Campinas for the HRTEM measurements.

\section{References}

1. Bhattacharyya, K. G.; Gupta, S. S.; Colloids Surf. 2006, 277, 191.

2. Koyuncu, H.; Kul, A. R.; Yildiz, N.; Çalimli, A.; Ceylan, H.; J. Hazard. Mater. 2006, 141, 128.

3. Chantawong, V.; Harvey, N. W.; Bashkin, V. N.; Air Soil Pollut. 2003, 148, 111 .

4. Coles, C. A.; Yong, R. N.; Appl. Clay Sci. 2002, 22, 39.

5. De Leon, A. T.; Nunes, D. G.; Rubio, J.; Clays Clay Miner. 2003, 51, 58.

6. Farmer, V. C.; Spectrochim. Acta 2000, 56, 927.

7. Ghosh, D.; Bhattacharyya, K. G.; Appl. Clay Sci. 2002, 20, 295.

8. Jain, C. K.; Ram, D.; Water Res. 1997, 34, 154.

9. Mellah, A.; Chegrouche, S.; Water Res. 1997, 31, 621.

10. Manohar, D. M.; Noeline, B. F.; Anirudhan, T. S.; Appl. Clay Sci. 2006, 31, 194.

11. Moore, D. M.; Reynolds Jr, R. C.; X-ray Diffraction and the Identification and Analysis of Clay Minerals, $2^{\text {nd }}$ ed., Oxford University Press: Oxford, 1989.

12. Bayramoglu, G.; Bektas, S.; Arica, M. Y.; J. Hazard. Mater. 2003, 101, 285.

13. Tunney, J.; Detellier, C.; Clays Clay Miner. 1994, 42, 473.

14. Gardolinski, J. E.; Wypych, F.; Cantão, M. P.; Quim. Nova 2001, 24,761 .

15. Costanzo, P. M.; Giese Jr., R. F.; Clays Clay Miner. 1985, 33, 415.

16. Naamen, S.; Jemai, S.; Ben, R. H.; Ben, H. A. A.; J. Appl. Crystallogr. 2003, 36, 898.

17. Valášková, M.; Rieder, M.; Matejka, V.; Capkova, P.; Silva A.; Appl. Clay Sci. 2007, 35, 108.

18. Ledoux, R. L.; White J. L.; Silic. Ind. 1967, 32, 269.

19. Airoldi, C.; Machado, M. O.; Lazarin, A. M.; J. Chem. Thermodyn. 2006, 38, 130.
20. Guerra, D. L.; Pinto, A. A.; Airoldi, C.; Inorg. Chem. Commun. 2008, 11, 539 .

21. Guerra, D. L.; Airoldi, C.; Viana, R. R.; Inorg. Chem. Commun. 2008, 11, 20.

22. Karadag, D.; Koc, Y.; Turan, M.; Ozturk, M.; J. Hazard. Mater. 2007, 144, 432.

23. Tunney, J. J.; Detellier, C.; Chem. Mater. 1996, 8, 927.

24. Volzone, C.; Thompson, J. G.; Melnitchenko, A.; Ortiga, J.; Palethorpe, S. R.; Clays Clay Miner. 1999, 5, 647.

25. Grim, R. E.; Clay Minerals, $5^{\text {th }}$ ed., McGraw-Hill: New York, 1968.

26. Yu, B.; Zhang, Y.; Shukla, A.; Shukla, S. S.; Dorris, K. L.; J. Hazard. Mater. 2000, 80, 33.

27. Frost, R. L.; Tran, T. H. T.; Kristóf, J.; Clay Miner. 1997, 32, 587.

28. Temkin, N.; Kadinci, E.; Demirbas, Ö.; Alkan, M.; Kara, A.; J. Colloid Interface Sci. 2006, 89, 472.

29. Ho, Y. S.; Ng, J. C. Y.; Mckay, G.; Sep. Sci. Technol. 2001, 36, 241.

30. Wada, N.; Raythatha, R.; Minomura, S.; Solid State Commun. 1987, 63, 783.

31. Tran, H. H.; Roddick, F. A.; O’Donell, J. A.; Water Res. 2003, $7,471$.

32. Chu, K. H.; J. Hazard. Mater. 2002, 90, 77.

33. Ho, Y. S.; Water Res. 2006, 40, 119.

34. Murray, H. H.; Appl. Clay Sci. 2000, 17, 207.

35. Chiron, N.; Guilet, R.; Deydier, E.; Water Res. 2003, 37, 3079.

36. Gökmen, V.; Serpen, A.; J. Food Eng. 2002, 5, 221.

37. Kuan, W. H.; Lo, S.-L.; Chang, C. M.; Wang, M. K.; Chemosphere 2000, 41, 1741.

38. Kithome, M.; Paul, J. W.; Lavkulich, L. M.; Bomke, A. A.; Soil Sci. Soc. Am. J. 1998, 62, 2836.

Received: December 7, 2007

Web Release Date: October 16, 2008

FAPESP helped in meeting the publication costs of this article. 